\title{
Some Aspects of Communication Via Electronic Mail (E-mail)
}

Ivan Pogarcic ${ }^{1}$, Marko Pogarcic ${ }^{2}$, Ida Panev ${ }^{2}$

${ }^{1}$ Polytechnic of Rijeka, Business Department

Vukovarska 58, 51000 Rijeka, Croatia

pogarcic,ida.panev@veleri.hr

${ }^{2} \mathrm{MSc}$ in Law, Law Novice

51000 Rijeka, Croatia

mpogarcic@gmail.com

ABSTRACT: Electronic mail can be considered from several aspects. Nonetheless, electronic mail should be primarily observed as a form of human communication. The way it is being realized is less important. Since electronic mail is the human form of communication, it necessarily connotes specific forms of human behaviour. Each deformation of that behaviour should be observed through the prism of generally accepted social norms. While those norms reflect cultural, ethical and moral frames of some (specific) social community, they should be respected. In such circumstances, electronic mail communication's participants can anticipate different situations. Some of those should be isolated, removed or sanctioned. The paper offers a comprehensive overview and treatments of different attempts of deceit using the email owned by one of the authors, within a time period of four years.

Keywords: E Mail, Short Communication, Social Communication, Human Communication

Received: 22 August 2018, Revised 18 October 2018, Accepted 29 October 2018

DOI: $10.6025 /$ jisr/2019/10/1/24-28

(C) 2019 DLINE. All Rights Reserved

\section{Introduction}

Communication doesn't belong solely to the human species. Still, human communication is the most important feature that distinguishes humans from other living species. However, only the human being demonstrates a need for speech respectively verbal communication. Finally, with the discovery of computers and simultaneous development of computer sciences and technical possibilities, communication has become a segment of web and global networking of all levels: private and professionals.

This paper will not explore all areas in which damages can occur due to data misuse, neither will analyse all aspects or possible consequences of those misuses. Paper however tries to frame those tendencies and attempts within the scope of human 
communication, especially communication practiced via electronic mail. Defining generic framework can provide a possibility for discussing all necessary elements of such communication. Aside from defining structural connections and possible setups of such communication, this paper also considers cultural, ethical and moral frame (s) which enable electronic mail communication. Definition of any of the above described frames assumes existence of a community which accepts all generally adopted social norms. These norms are, among others, determined by the level of community's development. From this paper's aspect, these norms define basic communication elements, considering it as a meaningful process. Due to the specificity of electronic communication, special regulations must be enforced.

The research approach used in this paper is conservative while it assumes there are modalities and possibilities of inappropriate, in the extreme circumstances, even criminal behaviour which can occur. An assumption that electronic mail deceit is a purposeful, intentional and profound violation of legal, moral, cultural and ethical norms of the society in which electronic mail is used is also conservative. The paper engenders a research in which authors explored legal articulation of the same problem, respectively determination of material and factual circumstances in which a specific form of deceits could happen - e- Crimen.

\section{Regulation of Relations in Electronic Communication - in General and Specific}

In simple terms, communication represents interaction between two or more elements, which are, due to a specific reason, oriented one towards the other. In system theory, communication is bipolar relationship between emitter / sender and receiver of the "substance" exchanged during the communication. Usually communication isn't necessarily bounded by direction so it can be altered, e.g. sender and receiver can change roles during the process. "Substance" is, though not necessarily, data or information shaped in form usually called a message. Information theory defines such a process as communication channel.

From this standpont, communication can be observed as generator of changes within a society. In the process it is important to monitor quality of both changes and causes developed due to those changes. In such circumstances, electronic mail can be observed as a product of human needs for communication. Post as communication tool, including electronic mail, basically represents a private relationship between sender and receiver, while as transmitter - post represents an organisation or modality which provides privacy. Traditionally, as within a state, post was developed institutionally on the highest level of social administration.

Since this relation is under the state's authority, its regulation is set by the corresponding law. Law prescribes conditions and modalities of post traffic organisation, but also determines sanctioning of irregularities and defines modes of indemnification of eventually damaged entity and sanctioning the offender. The specificity of post refers to the modes of transferring messages. Electronic post depends upon its communication infrastructure. Regulation of electronic post is therefore mainly set on the state level and/or under the state agencies' authority, e.g. telecommunication and electronic media agencies. Within those laws the electronic mail concept has been defined. To be more specific, the Croatian Law on Post would represent lex generalis, respectively a general law. Concept of electronic mail has been regulated by the Article 2 Paragraph 11 of Law on Electronic Communication [1]. The authors explored legal regulation and standardization in details within the preliminary part of research published in [2]. To be more concrete, the Council of the Croatian Agency for Post and Electronic Communications has passed the Rulebook on methods and conditions of preventing and moderating abuses and deceits in providing the services of electronic mail [1]. The above mentioned paragraphs of the Agency's Rulebook clearly imply the Republic of Croatia has defined formal frames for criminal practices within the national level, that are also aligned to the regulations adopted by the European Union legal entities.

The referred Rulebook was used in further discussion when defining unwanted electronic mail as "every message that without a specific reason emerges in electronic inbox of the subscriber". In such circumstances electronic mail is significantly distanced from the norms of traditional post traffic and communication. For instance, within traditional mail there are always the material evidences of attempts and possible realisation of violation that can be used in the eventual dispute.

According to the authors, e-Crimen describes every violation that can be legally defined, regulated, solved and sanctioned by corresponding legal acts adopted by the social community in which e-Crimen emerged [2].

\section{Preliminary Settings}

The first research conducted by the authors during 2011 also analysed electronic mail and inappropriate behaviour of the participants. At the time, authors tried to develop certain hypotheses starting with their own experiences and attitudes. The

Journal of Information Security Research Volume 10 Number 1 March 2019 
practical segment of research analysed a research problem from the aspect of post traffic, organisation of telecommunication infrastructure, and legal regulation of post traffic from the standpoint of basic information concepts and relations.

The next two years set the research towards defining material and factual frames which accompanied the attempt of deceit or generally inappropriate behaviour in electronic communication that could have damaged some of the participants. Hence, the problem was observed from the legal standpoint with an attempt to detect and assimilate data mostly connected to the virtual surrounding with the possible realistic consequences. Research has been processed and published during the January 2015.

This paper represents an analysis of the complete data including those gathered within period of the last years or the last eleven months, to be more specific. Opposite to the prior research, this paper tries to determine a psychological profile of individuals, the participants of electronic mail, whose behaviour in communication isn't appropriate from several different aspects. From the beginning of data gathering till their processing for the purpose of this paper, data did vary slightly in their meaning, so the classification of deceits' attempts also slightly changed compared to the one the authors developed in their original paper. For the purpose of this paper 717 attempts of communication via electronic mail, sent by the unknown sender, were selected (among totally 932 attempts). The repeated attempts have been numbered only once. According to data on motives and intentions of sender and confirmation of receipt, the authors checked whether a sender was malevolent or not.

Collected data of interest for this research implied that: The possible personal data of sender are usually wrong. Domain and sub-domain which contain account of the sender were usually of the general character, such as .com or .org. Location cannot be determined without a profound data analysis. Since sender and receiver do not know each other, a motive can only be assumed. Day and time of sending mail - data analysis has implied the majority of attempts have been made in the first part of the week with the peek being on Wednesday. Time period usually included the hours of break between 12:00 and 13:00 a.m. Advices for the possible actions of sender were in compliance with the analysed data [2].

With these regards, the following frame has been set: Electronic mail is a form of communication in which senders aren't always known or they can be falsely introduced. The sender can purposefully or unintentionally send electronic mail and thus harm the receiver by violating legal frames. Causes for inappropriate activities within electronic mail sphere can be classified but there is no generally accepted scientifically based practice. Psychological profile of the sender attempting a violation can be generally defined through the cultural and education frames which contain his/her e-account. Psychological profile of the offender can be defined according to the general guidelines of the cultural level. The chosen criterion of classification is submitted to the cause of research and at the same time is the research goal [2] .

\section{Frame Profile - Cultural Framework}

Inappropriate communication via email is momentarily an everyday phenomenon. Usually this sort of communication refers to theft and deceit. These type of attempts can be categorized and valued by giving them a specific severity. Still, it should be noticed the research sample so far included only that part of population with the access to the Internet and corresponding infrastructure. Due to inappropriate treatment of the participants and objects in electronic mail, it is important to profile them correctly. All irregularities in communication do not necessarily have to be intentional and quite often can emerge as a consequence of the participants' ignorance and lack of information. When these irregularities are intentional, then it is quite certain their initiator knows how to cause them. If the final result is a fraud or deceit, then the initiator becomes a violator who should be sanctioned. It is also important to specify the location where inappropriate activity has been initiated. Especially when that location refers to the working place. The violation in that case becomes multiple. The receiver doesn't necessarily know all the techniques and methods the violator uses, but by intentionally participating in communication he/she is put into a situation where he takes a part of the responsibility. The third part is the possible irresponsibility of the service provider - telecommunication operator. Electronic mail assumes the following terms and relationships: Email is the communication of the conventional post relationship type, but being put in the specific environment; The environment represents a combination of the realistic and virtual environment and the realistic environment is partially included. The participants are voluntarily communicating, as long as they want to; The participants don't necessarily have to know each other; The motive of communication can be unbeknown to all participants; Communication is timely discontinued but it does have a duration time, unknown at the beginning of the process; The possible negative consequences for the participants can be noticeable, but usually are not familiar. The above stated arguments are implying the inappropriate activities in e-Communication having all the characteristics of the e-Crimen, from the benign form of e-Crimen to its fullest scope.

$26 \quad$ Journal of Information Security Research Volume 10 Number 1 March 2019


By conducting a multiannual research and collecting data, the authors tried to approach this issue from several different aspects. After considering development of e- Post and insisting on the legal formulation in wider, even global frames [2], this part of research has been focused on the following problem: Who is the initiator of the misconduct as a physical person and what is the real cause of such behaviour?

From this standpoint, the above formulated question can represent the main hypothesis of this paper that can be supported through analysing and processing the collected data. In a certain manner, this type of approach has a forensic characteristics: If the inappropriate behaviour in e-Communication is a violation or a crime, then there has to be a motive for such behaviour; If there is a motive, then it surely is a consequence of the environment and the society in which the initiator lives; The circumstances and the environment directly influence the violator through their laws, cultural relationships and behaviours.

The above described features determine a profile of the offender. However, email in a certain manner dehumanizes communication since participants are mutually separated in their realistic environments. Hence it can be assumed one of the answers to the articulated hypothesis is the following: The initiator of the misconduct in e-Communication is a person who is being in the state of cognitive dissonance, in so far he/she is convinced he is not conducting a violation that can usually be sanctioned, or he/she momentarily has a distorted system of beliefs, values and ideas. Distortion can be a consequence of the approach to the information that in any way collide with the generally accepted values. For the purpose of this paper, authors accept a definition of cognitive dissonance [3],[4]. Personality represents an individual's characteristics that differ him from the others. According to [5], personality stands for "unique and unlimited part of our lives that differs us from the others". Personality is defined by cultural identity and it represents a measure of specificity that also defines identity. Further on, identity represents a feature, according to which, an individual gradually develops towards his environment, people and objects [6]. The second dimension of personality and identity is cultural. Cultural personality or cultural identity is also a feature that differs an individual from the other participants of a group or a culture or vice versa, that identifies him/her as a participant of a certain group [7].

By considering attitudes and opinions of some authors upon cultural characteristics, the authors of this paper made a conclusion there are features generally applicable to all people and human communities. According to these features, an inherent part characterized for each cultural institution can be defined, starting from the individual up to the general frames. Most authors use a set of next seven features: Art\&literature, Goverment, Language, Social Organization, Religion and Customs and Traditions. When an individual, identified through this frame, faces a virtual environment, his/her beliefs, ideas and attitudes can be threatened by the possibilities and information he can confront in e-Communication. It can be claimed language acquires new dimensions. Finally, this all can emerge in the environment such as e-Business, e-Economy or e-Money.

Defining a motive depends upon specifying relevant factual and material circumstances in which communication arises. The consequences can also be presumed is such case, at least hypothetically. Still, it is necessary that participants know the motive of sending email, at least to some measure. However, if the communication participants don't know each other, the motive can only be assumed. Data that have been collected and categorized during a period of four years, imply the final motive always to be the economic benefit of the sender. Since sender is the initiator of the process, a motive is usually his/her. Analysed data imply a motive is usually covered by the mutual benefits, while the final intent is to deceit the receiver. Smaller amount of the analysed cases belong to the area of the matrimonial and sexual offers. Only a minor part can be treated as business criminal.

\section{Analysis of the Collected Data}

Aside from the attempt to locate sender and gather data on him, analysis of time of writing and sending emails has also been made. It is assumed the majority of messages occur beyond the working hours. If messages occurred in period between 8:00 a.m. - 17:00 p.m., these could have been written on the job, presuming the sender works. Messages occurred on weekends were usually written at home.

Analysis implies majority of emails were sent in the middle of the week respectively on Wednesday while on weekends the activities were reduced for almost one third. Comparison was therefore made by using data for Wednesday and Sunday as days with the most and least activities. Even the original research showed that communication attempts are being grouped around lunch breaks, during the work days and weekends. The assumption is senders then have the most spare time while more detailed analysis of other days, implied a similar distribution for other working days with most activities happening after the break. In the same manner, more intensified activity during a week may imply messages are being sent usually from workplaces. Naturally, under the condition the sender is employed, which means he/she is making yet another violation - the malpractice of working

Journal of Information Security Research Volume 10 Number 1 March 2019 
assignments with a possible damage made to the employer. Email is unified by the computer screen standards, with the possibility of attaching different files. If there are limitations in formal perspective, these are connected to telecommunication infrastructure. Data on communication participants should be mentioned aside the protection mode of the unwanted senders. However, attention should be given to the post content, the object used in communication and the most important semiotic characteristics. Every e-message is written in some language so its content is determined by certain syntactic rules. The message content has a specific sense respectively semantic side that can be used to derive certain conclusions in need of a more detailed analysis. Nevertheless, the most important is pragmatic side that emessage should provide. This is the field of speculation and possible violations and disputes. Clearly there is at least triple pragmatic approach while the same problem will be perceived differently by the sender, receiver and telecommunication operator.

Analysing collected data, the authors tried to recognize pragmatic approaches of senders from the pragmatic aspect of the receiver. This was also a criterion for classification and categorization of the data. The criterion was developed by authors, while mode was an attempt of recognizing the primary goal of sender. The overview is given in table and on the following diagram. Most messages were of financial character and offers were connected to intermediation in transferring a large sum of money or notifications of the unexpected gains in lotteries and fortune games. This is followed by random messages with the attempts of gaining the humanitarian acceptance for different actions. The third type of message refers to the health, where the receiver is being convinced on the value of the advertised products.

\section{Conclusion}

Email is a specific form of communication realised through the combination of realistic/physical activities and colloquially named virtual activities. Still this virtual environment can be realised only through the physical activities. Nevertheless, the progress in technical aspects is not supported by the appropriate changes and development of the communication participants. The conducted research and analysis of the collected data imply inappropriate behaviours of e-Communication participants originate from the fact that cultural, ethical and moral frames do not follow described changes. The user is easily put in the condition of cognitive dissonance - purposefully or unintentionally. Still, the primary intent doesn't necessarily have to be negative. One fact is beyond question: if the sender is cognitively dissonant, the receiver doesn't have to be in the same position. However, by accepting the communication, receiver can be in induced dissonance. The appropriate answer to these problems, whether of technical, moral or ethical background, demands primarily more intensive education in the all mentioned areas. However, the education itself isn't enough. As a legal process, e-Communication demands corresponding tools and modalities for sanctioning the misconduct. Usually these are the frames that follow a general development of individuals and communities in whole. The possible specificities of certain community shouldn't be a source of negativities in e-Communication.

\section{References}

[1] Official Gazette 73/08, 90/11, 133/12, 80/13, 71/14; further referred to as LEC.

[2] Pogarcic, I., Pogarcic, M. (2013). Some aspects of (attempted) fraud via e-mail. In Advances in Business management, 3rd Business Systems Laboratory International Symposium. Perugia, Book of abstracts, p 162.

[3] Festinger, L. A Theory of Cognitive Dissonance. California: Stanford University Press. 1957.

[4] Festinger, L. Cognitive dissonance. Scientific American 207 (4). p. 93-107. 1962.

[5] Chambers, O. (2000). My Utmost for His Highest. Barbour Books, ISBN-13: 978-1577489146.

[6] Pratt, D. D. (2005). Teaching. In L. M. English. International Encyclopedia of Adult Education. New York: Palgrave Macmillan.

[7] Gans, H. (2003). Democracy and the news. Oxford University Press. 2003.

[8] http://www.web.books.com/eLibrary/NC/B0/B58/052M B58.html, downloaded on 10.5.2015.

$28 \quad$ Journal of Information Security Research Volume 10 Number 1 March 2019 